\title{
Indicadores de Alfabetização Científica: um estudo em espaços não formais da cidade de Toledo, PR
}

\author{
Matheus Ferreira \\ mathaws@hotmail.com \\ Universidade Estadual do Oeste do \\ Paraná (Unioeste), Cascavel, Paraná \\ Brasil \\ Gabriela Ledur Alves \\ gabriela ledur@hotmail.com \\ Paraná (Unioeste), Toledo, Paraná, Brasil \\ Márcia Borin da Cunha \\ borin.unioeste@gmail.com \\ Universidade Estadual do Oeste do \\ Paraná (Unioeste), Toledo, Paraná, Brasil \\ Rosana Franzen Leite \\ rosanafranzenleite@gmail.com \\ Universidade Estadual do Oeste do \\ Paraná (Unioeste), Toledo, Paraná, Brasil
}

\section{RESUMO}

O presente trabalho apresenta um estudo sobre os seguintes espaços de educação não formal presentes na cidade de Toledo/PR: Parque das Aves e Aquário Municipal Rômolo Martinelli, ambos instalados junto ao Parque Ecológico Diva Paim Barth e ao Museu Histórico Willy Barth. Para esse estudo foi realizada uma entrevista focalizada com os coordenadores dos espaços, para identificar como são realizadas as atividades, bem como e quais sãos os seus principais frequentadores. Após as transcrições das entrevistas, foi então realizada uma análise de conteúdos, análise essa baseada nas lições da professora francesa Laurence Bardin. As categorias são de acordo com os indicadores de Alfabetização Científica, segundo a professora Tânia Maria Cerati, que são: (i) indicador científico, (ii) indicador institucional, (iii) indicador interface/social e (iv) indicador estético/afetivo. A análise forneceu subsídios para concluir que os espaços recebem visitantes de diversas cidades do Brasil, bem como do exterior, no entanto os principais visitantes são estudantes de escolas municipais da cidade. Identificamos também que diversas atividades são realizadas nesses espaços, sendo que elas podem proporcionar diferentes conhecimentos aos que os visitam.

PALAVRAS-CHAVE: Cultura científica. Museus. Aquário. Horto florestal. Divulgação científica. 


\section{INTRODUÇÃO}

Refletindo sobre todas as atividades que realizamos durante o nosso dia, podemos identificar que essa movimentação diária, apresenta diferentes tipos de conhecimentos, sejam eles de senso comum, científicos e/ou tecnológicos. É possível dizer, então, que a ciência e a tecnologia estão presentes em nosso cotidiano, mas até onde conseguimos identificar essa ciência? Conseguimos vê-la em um parque? Em uma igreja? Em um museu de História? Em uma praça? São poucas as pessoas que param para observar essas situações. Então como poderíamos detectar um pouco desse conhecimento para que tenhamos um olhar mais crítico sobre os acontecimentos do nosso dia a dia? E qual seria o melhor momento ou a melhor época para proporcionar aos seres humanos o início dessas reflexões sobre a ciência/tecnologia, senão no início das atividades escolares na infância e adolescência?

Pensando nisso, apresentaremos uma breve discussão sobre fatores relevantes que podem promover reflexões sobre Ciências, tanto para crianças, quanto para jovens e inclusive adultos.

\section{ALFABETIZAÇÃO CIENTÍFICA}

Cada vez mais se tem falado da importância em se formar um cidadão crítico e atuante na sociedade, em especial sobre assuntos do dia a dia. Acreditamos que a Alfabetização Científica vem ao encontro dessa perspectiva, buscando proporcionar ao estudante uma visão mais crítica do mundo onde vive.

A expressão Alfabetização Científica (AC), do inglês "Scientific Literacy", foi apresentada ao meio acadêmico no livro "Science Literacy: Its Meaning for American Schools", publicado em 1858 pelo norte-americano Paul Hurd, livro esse que passou a ser estudado por diversos pesquisadores em diferentes regiões do mundo. Em decorrência disso, sua polissemia aumentou, fazendo com que o termo Alfabetização Científica, que começou a ser estudado no Brasil, apresentasse diferentes traduções e, consequentemente, diferentes sentidos e significados (SASSERON; CARVALHO, 2011).

Apresentaremos alguns pesquisadores que colaboraram para a definição do termo AC. Insistimos numa definição mesmo sabendo que DeBoer (2000) já nos aconselhava que "[...] devemos aceitar o fato de que a AC é simplesmente sinônima da compreensão pública da ciência e que se trata necessariamente de um conceito amplo [...]" (DEBOER, 2000, p. 594, tradução nossa).

Buscamos realizar uma pesquisa bibliográfica em diferentes arquivos, como, por exemplo, livros, artigos, dissertações e teses, pesquisa na qual, a partir desse material, conseguíssemos encontrar algumas definições consistentes de AC.

Uma das primeiras definições encontradas, foi aquela proposta por Pella, O'Hearn e Gale (1966). Para eles, um sujeito alfabetizado cientificamente é aquele que:

[...] estabelece relações entre ciência, sociedade e humanidades e diferencia ciências de tecnologia, visualizando a natureza da ciência e a ética que 
das ciências a fim de perceber e entender as inter-relações entre as ciências e o cotidiano [...]. (CERATI, 2014, p. 29).

Como podemos perceber, esses autores consideram como cidadão alfabetizado cientificamente aquele que consegue entender as relações entre a ciência e a sociedade, entre conhecimentos científicos e o seu cotidiano.

Outro autor que merece destaque sobre os estudos da AC é Shen (1975), que teve o seu trabalho citado por diversos autores que o definem como um estudioso clássico da AC (ROBERTS, 2007; SASSERON, CARVALHO, 2010; LAUGKSCH, 2000; LEITE, 2015)).

Shen (1975) propõe três dimensões para a AC:

a) Prática - relacionada com a aquisição de um tipo de conhecimento científico que o auxilia a resolver problemas práticos, tais como saúde e sobrevivência;

b) Cívica - habilita os cidadãos a se tornar mais conscientes sobre as questões relacionadas à/com a ciência, para tomada de decisões e atuação participativa no processo democrático dentro de uma sociedade cada vez mais tecnológica;

c) Cultural - relacionada com a motivação de saber mais sobre a ciência como uma grande conquista do conhecimento humano (SHEN, 1975 apud CERATI, 2014, p. 29-30).

Dentre as três dimensões propostas, a dimensão cultural pode contribuir com a motivação dos cidadãos para a busca de novos conhecimentos relacionados à ciência e às suas relações com o cotidiano. Além do mais, Shen apresenta relações da divulgação da ciência de diferentes formas, promovendo assim aos cidadãos uma AC (CERATI, 2014).

Quando falamos sobre AC, encontramos outra definição proposta por Rodger W. Bybee (1995), citado por Escodino e Góes (2013). Esse autor propõe que a AC pode ser classificada em cinco dimensões, ou seja, um cidadão pode apresentá-la em diferentes níveis, dependendo do assunto a ser discutido. Os níveis apresentados por Bybee (1995) são:

- Nominal - aquele em que o aluno já ouviu falar nos termos científicos em questão, mas não sabe defini-los.

- Funcional - aquele em que o aluno já sabe definir os termos científicos em questão, mas não faz ideia do que realmente significam.

- Conceitual - aquele em que o aluno já sabe definir os termos científicos e realmente se apropria de seus significados, mas não sabe estabelecer relações entre esses termos para resolver problemas do cotidiano.

- Procedimental - aquele em que o aluno é capaz de definir termos científicos e correlacioná-los para resolver questões do seu cotidiano, mas que restringe essa capacidade a termos de uma área da ciência, como a Biologia Molecular por exemplo.

- Multidimensional - é o estágio final da alfabetização científica, quando o aluno é capaz de mobilizar conhecimentos de diferentes disciplinas que já domina em nível Procedimental para resolver problemas do seu cotidiano (BYBEE, 1995 apud ESCODINO; GÓES, 2013, p. 556). 
Em relação às contribuições de Bybee (1995) sobre a AC, é importante considerar que as suas propostas têm como foco a associação dos conhecimentos científicos a atividades e situações desenvolvidas em sala de aula.

Nesse sentido, o autor destaca que, para os estudantes apresentarem uma AC funcional, eles devem saber ler e escrever textos usando o vocabulário científico, ou seja, saber utilizar termos específicos da ciência.

Já sobre a AC conceitual, ela se faz presente quando os estudantes já sabem definir os termos científicos, no entanto apresentam dificuldade de aplicá-los a situações do seu dia a dia. $\mathrm{O}$ que se contrapropõe à dimensão procedimental, onde o estudante consegue se apropriar ao vocabulário científico e relacioná-lo às atividades realizadas em sua comunidade, ou seja, quando já se espera que tome posse dos conhecimentos relacionados à ciência, e consiga construir relações sobre o mundo em que está inserido.

Já a AC multidimensional é aquela que ocorre em situação em que os estudantes têm o conhecimento sobre o vocabulário científico, sabem utilizá-lo em diversas situações de maneira adequada e compreendem a importância da ciência para o desenvolvimento da tecnologia, bem como as suas relações com os fenômenos da natureza, entendendo que a ciência está presente em suas vidas (SASSERON; CARVALHO, 2011).

Nosso trabalho, no entanto, tem como base os indicadores apresentados por Tânia Maria Cerati (2014), em seu trabalho intitulado Educação em Jardins Botânicos na Perspectiva da Alfabetização Científica: análise de uma exposição e público. Nesse trabalho, a autora apresenta quatro indicadores de AC: (i) indicador científico, (ii) indicador institucional, (iii) indicador interface/social e (iv) indicador estético/afetivo. Apresentamos a seguir um breve comentário sobre cada um deles.

No primeiro, no indicador científico, são analisadas questões que tendem a contribuir para a $A C$ e que possibilitem meios para que os visitantes construam conhecimento sobre assuntos científicos expostos.

Já no segundo, no indicador institucional, são apresentadas informações a respeito da instituição onde foi realizada a atividade. Esse indicador pode ser relacionado às atividades científicas desenvolvidas e à sua função social, cultural e histórica.

O terceiro indicador, o da interface social, aparece quando a exposição ou atividade possibilita a compreensão da aplicação do conhecimento científico em situações cotidianas: "Esse indicador favorece o entendimento do significado social da ciência e explora as inter-relações entre as esferas científicas, tecnológicas, social e ambiental" (CERATI, 2014, p. 82).

E finalmente no Indicador Estético/Afetivo, é caracterizado quando por apresentar aspectos que despertam um conjunto de emoções, sensações, observações e sentimentos, a partir das atividades realizadas durante a visita. Com base nesses indicadores serão elaboradas nossas categorias. Partindo disso, apresentaremos a seguir nossos resultados. 


\section{DIVULGAÇÃO CIENTÍFICA}

Conseguimos identificar também, na literatura, uma área paralela à AC. Tratase da Divulgação Científica (DC) e essa área tem um papel de destaque entre os pesquisadores da área de Educação em Ciências. Muitos consideram que a DC pode ser um excelente instrumento para auxiliar os professores em sala de aula.

Refletindo sobre isso, surgem alguns questionamentos do tipo: -Como pode um país, em que o número de pesquisas em educação em ciências vem crescendo, ser ainda um dos piores a nível global? -Como nós, enquanto professores, podemos realizar algo para mudar os rumos da educação em ciências em nosso país? -Quais são os meios e os recursos que poderiam ser utilizados para tal mudança?

Sabemos que, para responder a tais questões, seria necessária uma pesquisa mais ampla. Podemos, porém, continuar a pensar em diferentes meios para melhorar a qualidade do ensino em nossas escolas. Por isso apresentamos, neste trabalho, uma proposta que utiliza a DC como apoio à educação formal. Para isso, precisamos, porém, entender um pouco sobre o que é a DC e as suas relações com os Documentos Nacionais, bem como são as suas relações com os diversos espaços informais e não formais de educação.

A Base Nacional Comum Curricular (BNCC) é uma construção coletiva que pretende estabelecer os objetivos gerais de aprendizagem a todos os estudantes, desde a Educação Básica até o final do Ensino Médio. Em abril de 2016 foi realizado um debate sobre a sua possível aprovação. Dessa forma, buscamos realizar uma pesquisa sobre os pontos de destaque da Divulgação Científica na BNCC, onde encontramos as seguintes orientações: "O campo investigativo possibilita conhecer os gêneros, a linguagem e as práticas relacionadas ao estudo, à pesquisa e à divulgação científica, favorecendo a aprendizagem dentro e fora da escola" (BRASIL, 2016, p. 525).

Nota-se que o documento apresenta a DC como um instrumento de auxílio na aprendizagem dos estudantes dentro e fora da sala de aula, no sentido de que eles possam conhecer o gênero e as práticas de linguagem, permitindo assim a relação do conteúdo estudado em sala de aula com o seu cotidiano.

A fim de identificar quais as orientações sobre a Divulgação Científica para os professores da rede estadual de ensino, realizamos uma busca nas Diretrizes Estaduais de Ciências, Física e Química, do estado do Paraná.

Encontramos, então, no documento de Química, as seguintes orientações:

[...] assistir a um filme, por exemplo, Óleo de Lorenzo e relacionar a produção e o acúmulo de ácidos graxos no organismo com as doenças degenerativas. Na sequência, fazer a leitura de um texto de divulgação científica sobre o mesmo assunto. É uma maneira de motivar o aluno para a leitura e um recurso que favorece questionamentos. (PARANÁ, 2008, p. 69).

Nas diretrizes de Química encontramos apenas uma citação relacionada à DC, a qual tem como proposta assistir a um filme (intitulado "Óleo de Lorenzo") e relacioná-lo a um tema, no caso, o tema dos ácidos graxos no organismo humano. Em decorrência disso, propõe-se ainda que os professores desenvolvam, com os estudantes, atividades baseadas em filmes e em textos de DC sobre o mesmo assunto. 
Já nas diretrizes de Física, nesse documento encontramos diversas citações sobre a utilização da DC na sala de aula. Dentre elas, destacamos:

Sobre a divulgação científica em sala de aula, existem muitos autores que produzem textos de divulgação científica em jornais, revistas, livros, e até mesmo na Internet, que podem ser utilizados pelo professor em sala de aula. (PARANÁ, 2008, p. 75).

Desse modo, as Diretrizes Curriculares do Paraná apresentam que a DC pode ser utilizada por diferentes meios, como: textos, filmes e vídeos. Cabe aqui destacar que nem as diretrizes de Química nem as de Física apresentam algo além das atividades com filmes, vídeos e textos. Quando, no entanto, realizamos a pesquisa nas diretrizes de Ciências, também no estado do Paraná, foi possível observar que, além de textos, filmes e vídeos, há a citação de visitas a Museus e a Centros de Ciências, com proposta de trabalho para os professores realizarem.

[...] ao optar pelo uso didático de materiais de divulgação científica, como revistas, jornais, documentários, visitas a Museus e Centros de Ciências, entre outros, precisa considerar que este tipo de material não foi produzido originalmente para ser utilizado em sala de aula e, por isso, requer uma adequação didática. (PARANÁ, 2008, p. 71).

Observamos aqui mais uma possibilidade para se utilizar a DC, que são as visitas em Centros de Ciências e Museus. As diretrizes ressaltam também que esse tipo de atividade não é originalmente produzido para a utilização em sala de aula, mas, sim, para um público leigo. Cabe a nós perguntar:-Como inserir espaços não formais nas atividades escolares? -Como espaços urbanos podem ser utilizados para a promoção da alfabetização científica? -Quais são as possibilidades e as relações que podem ser estabelecidas entre espaços não formais e a sala de aula?

\section{A DIVULGAÇÃO CIENTÍFICA E OS DIFERENTES ESPAÇOS DA CIDADE: ESPAÇOS INFORMAIS E NÃO FORMAIS DE EDUCAÇÃO}

Como apresentado anteriormente, as diretrizes curriculares educacionais do estado do Paraná propõem que, além de se utilizarem os textos de DC, os professores também possam usufruir de outros espaços de ensino, como Museus e Centros de Ciência. Assim, para que possamos nos aprofundar mais nessa discussão, buscamos identificar os diferentes espaços nos quais uma pessoa pode ser "educada".

Smith (2001) propõe que a educação pode ser realizada em diferentes espaços, sendo eles classificados como espaço formal, espaço não formal e espaço informal de educação.

A educação formal: cronologicamente classificada como "sistema de ensino" hierarquicamente estruturada, em execução desde o ensino primário até a universidade e incluindo, além de estudos acadêmicos em geral, uma variedade de programas e de instituições especializadas de formação técnica e profissional em tempo integral. 
ambiente - da família e dos vizinhos, de trabalho e diversão, a partir do lugar de mercado, da biblioteca e dos meios de comunicação de massa.

A educação não formal: qualquer atividade educativa organizada fora do sistema formal estabelecido - operando separadamente ou como uma característica importante de alguma atividade mais ampla - que se destina a servir de identificação de clientelas de aprendizagem e objetivos de aprendizagem. (SMITH, 2001, s/p. Tradução nossa).

Nesse sentido, os professores podem pensar em meios além da sala de aula, buscando recursos para o desenvolvimento de atividades diferenciadas, proporcionando aos seus estudantes maiores oportunidades para o desenvolvimento de uma alfabetização científica.

Partindo desse pressuposto, acreditamos que as cidades apresentam diversos espaços com potencial para o desenvolvimento de atividades didáticas em locais fora do ambiente escolar. Além disso, cidadãos que não se encontram mais nas instituições de ensino possam também procurar esses espaços a fim de adquirir novos conhecimentos, mesmo que em momentos de lazer.

Com base nessas concepções, foram entrevistados coordenadores de três espaços de educação não formal na cidade de Toledo-PR, sendo eles: Parque das Aves e Aquário Municipal Rômolo Martinelli, ambos instalados junto ao Parque Ecológico Diva Paim Barth e administrados pela Secretaria Municipal de Meio Ambiente, e o Museu Histórico Willy Barth, administrado pela Secretaria Municipal de Educação e Cultura. $\mathrm{O}$ objetivo das entrevistas foi identificar como as atividades desenvolvidas nesses espaços podem contribuir para a divulgação científica, bem como para a alfabetização científica dos visitantes.

\section{METODOLOGIA}

A pesquisa aqui desenvolvida é de caráter qualitativo, pois com ela buscamos analisar as informações contidas nas entrevistas realizadas com coordenadores. $O$ método de coleta de dados foi o de entrevista focalizada, técnica de obtenção de dados que, segundo Gil (2008), é aquela em que o entrevistador tem liberdade durante a entrevista fazendo perguntas abertas, podendo assim explorar amplamente a questão estudada. Normalmente, as perguntas abertas podem ser respondidas de maneira informal, permitindo que o entrevistado fale livremente sobre o assunto. Esse formato de entrevista é bastante utilizado em situações experimentais.

Para a coleta de dados utilizamos a gravação em áudio, que passou posteriormente por um processo de transcrição. Em seguida, os dados foram tratados e tabulados de acordo com a análise de conteúdo. Essa análise de conteúdo, segundo Bardin (2011) é

Um conjunto de técnicas de análise das comunicações visando obter, por procedimentos sistemáticos e objetivos de descrição do conteúdo das mensagens, indicadores (quantitativos ou não) que permitam a inferência de conhecimentos relativos às condições de produção/recepção (variáveis inferidas) dessas mensagens. (BARDIN, 2011, p. 48). 
Para a formação de nossas categorias utilizamos como referência o trabalho de Tânia Maria Cerati (2014), no qual a autora apresenta os seguintes indicadores: (i) indicador científico, (ii) indicador institucional, (iii) indicador interface/social" e (iv) indicador estético/afetivo.

Apresentamos a seguir nossas análises e resultados.

\section{RESULTADOS E DISCUSSÕES}

Para iniciar a discussão é importante apresentar o tipo de público que normalmente visita os três espaços investigados nesta pesquisa: Parque das Aves, Aquário Municipal e Museu Municipal Willy Barth.

A partir das entrevistas realizadas com os responsáveis pelos espaços, apresentamos o Quadro 1, no qual compilamos as seguintes informações.

Quadro 1 - Visitante dos locais pesquisados.

\begin{tabular}{|c|c|}
\hline LOC & do \\
\hline $\begin{array}{l}\text { Parque } \\
\text { das Aves }\end{array}$ & $\begin{array}{c}\text { [...] então a gente atende todos os alunos do programa conhecendo } \\
\text { Toledo ... e a gente atende de várias escolas e grupos da região [...] } \\
\text { [...] os grupos da APAE ... e de outras entidades que têm algum tipo de } \\
\text { deficiência grupos especiais [...] } \\
\text { [...] nosso maior público ... as crianças a gente recebe muitos idosos .... e } \\
\text { especiais ... a gente recebe também ... pessoal da área da assistência } \\
\text { social como menores infratores [...] }\end{array}$ \\
\hline $\begin{array}{l}\text { Museu } \\
\text { Municipal }\end{array}$ & $\begin{array}{r}\text { [...] Programa Roteiro Conhe } \\
\text { quarto ano } d \\
{[\ldots] \text { assim ... eu vejo que a proc }} \\
\text { fazer um turismo na cidade ... e } \\
\text { pouc } \\
{[\ldots] \text { recebemos també }} \\
{[\ldots] \text { temos uma exp }}\end{array}$ \\
\hline $\begin{array}{l}\text { Aquário } \\
\text { Municipal }\end{array}$ & 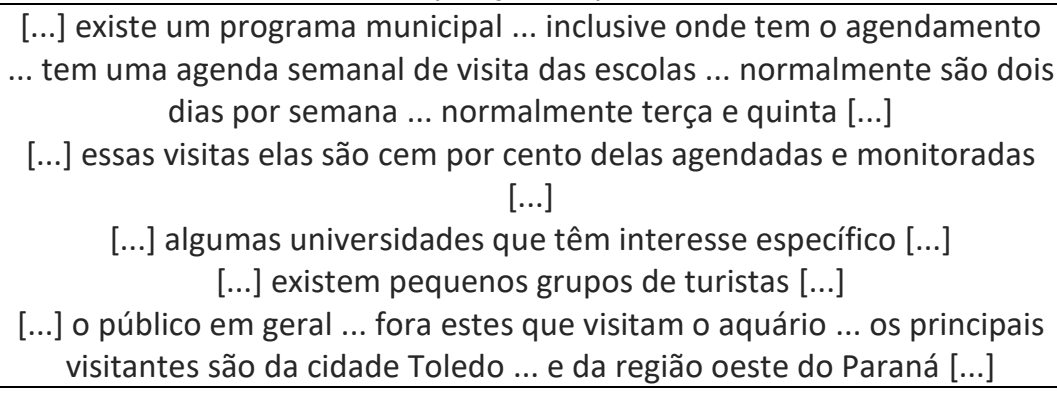 \\
\hline
\end{tabular}

Fonte: Autoria própria (2017).

Como podemos observar, a partir das respostas dos coordenadores, o público que realiza a visita é muito parecido, visto que os principais visitantes são alunos da rede municipal de ensino, participantes do Programa Conhecendo Toledo. Podemos identificar também que grupos de idosos e a APAE (Associação de Pais e Amigos Excepcionais) também realizam visitas nesses locais. Cabe destacar que o Museu também fornece uma sala itinerante que recebe diversas exposições durante o ano, sendo que uma delas é a exposição de obras feitas pelos estudantes da APAE. 
Sobre a população em geral que realiza a visita nesses locais, podemos destacar a fala da coordenadora do Museu, que afirma:

[...] visitação assim não é intensa do público [...] não conseguimos ainda buscar esse costume para buscar com que as pessoas venham e visitem, venha conhecer a história do município. Os que vêm e que acontece bastante, entre dezembro e janeiro, são visitantes de outros estados até de países [...] que vieram nos visitar também ano passado [...] assim eu vejo que a procura maior é de pessoas de fora que vêm fazer um turismo na cidade e que têm essa curiosidade de conhecer um pouco da história e conhecer o próprio museu $[\ldots]$.

Nesse caso observamos que os moradores da cidade de Toledo ainda não visitam com frequência o Museu. Diferentemente do que acontece no aquário municipal, onde seu responsável afirma que:

[...] como a grande maioria do nosso público não são turistas são pessoas da própria cidade de Toledo que vêm visitar o horto, então acontece assim o cara vem correr no final da tarde e vai para o aquário beber uma água relaxar um pouquinho e vai lá dar uma voltinha no aquário pra descontrair [...].

Podemos relacionar essa grande diferença de procura pela visitação devido à localização dos dois espaços, visto que o Museu está localizado na saída da cidade, enquanto o Aquário Municipal se encontra em uma região nobre da cidade, onde está localizado o Parque Diva Pain Barth (lago municipal, horto municipal, shopping...). Nesse local, as pessoas têm o hábito de realizar atividades físicas no final da tarde, bem como, reunir-se com familiares e/ou amigos para um momento de lazer.

Visto isso, buscamos então, a partir das entrevistas com os coordenadores, identificar como as atividades realizadas nesses espaços podem contribuir para a Alfabetização Científica dos visitantes. Selecionamos os principais trechos das entrevistas e as organizamos em quatro quadros, de modo a possibilitar uma melhor visualização das falas.

No Quadro 2 apresentamos o Indicador Científico. Para esse indicador selecionamos alguns trechos das falas dos entrevistados. São trechos que retratam a metodologia utilizada durante o monitoramento das atividades. Já aqui estamos antecipando que no Museu não foi encontrado nenhum indicador científico.

Quadro 2 - Indicador Científico

\begin{tabular}{|c|c|}
\hline Locais & Indicador Científico \\
\hline \multirow{3}{*}{$\begin{array}{l}\text { Parque } \\
\text { das Aves }\end{array}$} & $\begin{array}{c}{[\ldots] \text { trabalha com o conceito de trilha ecológica interpretativa ... que utiliza }} \\
\text { o método construtivista ... e também a gente faz algumas atividades dentro } \\
\text { da metodologia de aprendizado sequencial }[\ldots]\end{array}$ \\
\hline & $\begin{array}{l}\text { [...] a função do Parque como ferramenta de educação ambiental ... então } \\
\text { mais voltada a essa área de educação ambiental ... ao parque e os animais } \\
{[\ldots . .]}\end{array}$ \\
\hline & $\begin{array}{c}\text { [...] um público muito importante ... a gente oferece capacitação para } \\
\text { professores }[\ldots] \text { ao longo do ano a gente forma muitos professores ... para } \\
\text { atuar com esses temas nas escolas }[\ldots]\end{array}$ \\
\hline $\begin{array}{l}\text { Aquário } \\
\text { Municipal }\end{array}$ & $\begin{array}{c}{[\ldots] \text { o pessoal da Engenharia de Pesca ... vai muito lá para ver }} \\
\text { funcionamento de filtros [...] toda a explicação que precisa fazer o pessoal } \\
\text { da Arquitetura [...] }\end{array}$ \\
\hline
\end{tabular}




\begin{tabular}{c|c}
\hline$\ldots .$.$] se acontecer um derramamento de um agroquímico ... por exemplo no$ \\
rio Iguaçu ... e matar todas as espécies que tem lá ... pronto ... elas estão \\
extintas ... porque não existem mais em nenhum lugar do mundo ... elas \\
\\
$\begin{array}{c}\text { existem então pra esse tipo de público ... turista ... e mais interessante ... } \\
\text { esse contexto do que a poluição ... entende ... até porque a maior parte são } \\
\text { jovens ou adultos [...] }\end{array}$
\end{tabular}

Fonte: Autoria própria (2017).

Selecionamos aqui, para destaque, o trecho referente ao Parque das Aves, no qual a coordenadora salienta a importância em seguir a metodologia da trilha ecológica interpretativa. Essa metodologia tem se tornado muito importante no ensino da Educação Ambiental, especialmente em Reservas Ambientais e/ou locais onde é possível seu planejamento e execução. Ou seja, "A trilha é considerada interpretativa quando seus recursos são traduzidos para os visitantes, relacionando estes recursos, como as paisagens, a flora ou a fauna com os seres humanos" (MENGHINI; GUERRA, 2008, p. 5-6).

Para a realização de atividades como esta é necessário um planejamento adequado, para que ocorra a aproximação dos visitantes com o ambiente natural, possibilitando assim a realização de interpretações, bem como, das atividades, proporcionando uma experiência educativa não formal (PEREIRA et al., 2014). Nesse sentido, observamos que há um comprometimento dos responsáveis pelo espaço em proporcionar ao visitante um aprendizado, sendo que este é relacionado à Educação Ambiental.

Identificamos também que, no que diz respeito ao aquário, a preocupação na formação de conceitos relacionados à Ciência é para públicos específicos, como, por exemplo, estudantes de Arquitetura ou de Engenharia de Pesca. Para esses públicos a explicação é mais direcionada para a área de estudo. Diferentemente, em se tratando dos visitantes em geral, a explicação é mais direcionada aos impactos ambientais e às atividades do rio Paraná e do rio Iguaçu.

No Quadro 3 apresentamos os indicadores institucionais. Nesses indicadores podemos observar três linhas diferentes no processo de AC.

Quadro 3-Indicador Institucional

\begin{tabular}{|c|c|}
\hline Locais & Indicador Institucional \\
\hline $\begin{array}{l}\text { Parque } \\
\text { das Aves }\end{array}$ & $\begin{array}{c}\text { [...] como é o espaço lúdico ... a gente consegue aplicar algumas atividades } \\
{[\ldots . .]} \\
\text { [...] nós temos um roteiro ... a trilha toda dura um quilômetro ... às vezes a } \\
\text { gente não consegue fazer com que as famílias participem da Trilha toda [...] } \\
{[\ldots . . .] \text { ambientes não formais ... eles são incríveis para formação das pessoas ... }} \\
\text { até porque ele atinge um público que não está mais na escola ... e se não for } \\
\text { essa informação no espaço não formal ... ele não vai ter nenhum tipo de } \\
\text { trabalho sendo realizado de reflexão ... sendo realizada com esses temas ... } \\
\text { no nosso caso aqui educação ambiental [...] }\end{array}$ \\
\hline $\begin{array}{c}\text { Museu } \\
\text { Municipal }\end{array}$ & 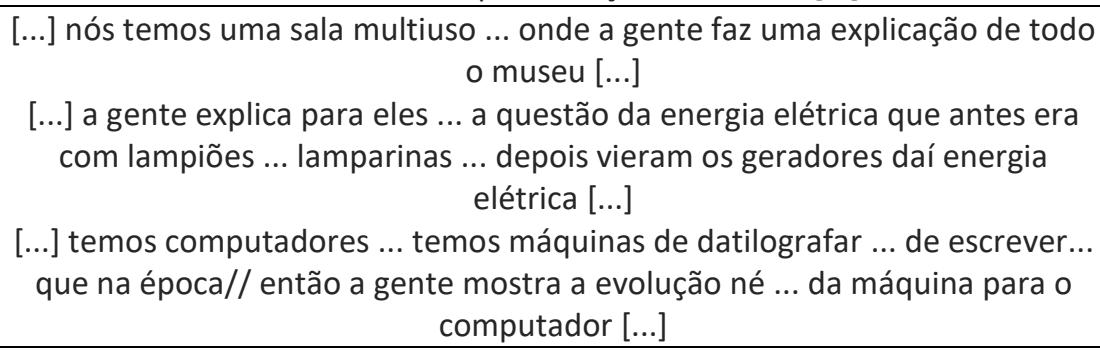 \\
\hline
\end{tabular}




\begin{tabular}{c|c}
\hline Aquário & $\begin{array}{c}{[\ldots . .] \text { normalmente o que se fala ... é principalmente o aspecto de educação }} \\
\text { ambiental ... com o tema é conservar o ambiente aquático ... preservar a } \\
\text { água coisas assim [...] }\end{array}$ \\
$\begin{array}{c}{[\ldots] \text { todo mundo morre de medo de piranha ... achando que piranha é um }} \\
\text { animal agressivo ... a gente trata esse tema com as crianças ... pra mostrar } \\
\text { que a piranha é um peixe como qualquer outro ... a gente fala que elas } \\
\text { colocam os ovinhos nas plantas ... e se alguém chegar perto elas protegem } \\
\text { seus ovinhos ... como a mãe deles protege seus filhos [...] }\end{array}$ \\
\hline
\end{tabular}

Fonte: Autoria própria (2017).

Referente ao Parque das Aves, observamos que a coordenadora aponta aspectos do desenvolvimento das atividades, bem como, sobre a importância dos espaços não formais de Educação, para a formação das pessoas. Nesse sentido há concordância com o que diz Gohn (2016, p. 30):

A educação não-formal tem outros atributos: ela não é organizada por séries/idade/conteúdos; atua sobre aspectos subjetivos do grupo; trabalha e forma a cultura política de um grupo. Desenvolve laços de pertencimento. Ajuda na construção da identidade coletiva do grupo (este é um dos grandes destaques da educação não-formal na atualidade);

Sendo assim, os visitantes podem aprender ao mesmo que tempo em que se atualizam sobre assuntos relacionados a ciência, nesse caso sobre educação ambiental, independentemente de sua idade, trabalho, escolaridade, gênero...

Já o Museu tem como principal característica, no desenvolvimento da Ciência, a evolução da tecnologia, que é abordada em diversos momentos da visita.

[...] o papel social dos museus torna-se então base para reflexões, possibilitando o repensar sobre a cultura museológica, rumo a adequações e mudanças de paradigmas, de forma a atender as demandas da sociedade moderna, cada vez mais interativa, conectada, gerando, produzindo, consumindo informação. Sobre isso podemos destacar que mesmo um museu da História do município pode e deve proporcionar aos seus visitantes um maior conhecimento a respeito da ciência, bem como o desenvolvimento da tecnologia. (MARTINS, 2016, p. 7).

Silva e Grynszpan (2015) salientam que, mesmo que a abordagem científica não esteja explícita em uma determinada exposição, cabe ao mediador proporcionar que os visitantes percebam essa abordagem. Por meio da mediação é possível instigar a curiosidade dos visitantes por determinado assunto.

A respeito do aquário, identificamos que uma das principais preocupações é referente à questão social. Com base nisso, procura-se informar os visitantes sobre a importância da educação ambiental, bem como desmistificar alguns saberes populares da região.

No Quadro 4 apresentamos os indicadores de interface/social. 


\begin{tabular}{|c|c|}
\hline Locais & Indicador Interface/social \\
\hline $\begin{array}{l}\text { Parque } \\
\text { das Aves }\end{array}$ & $\begin{array}{c}\text { [...] a gente construiu [...] uma revistinha para crianças ... como se fosse um } \\
\text { Gibi ... que tem brincadeiras ... historinhas ... que passa aqui em Toledo ... } \\
\text { que conta a história dos animais silvestre aqui na cidade ... essas relações do } \\
\text { lixo ... relações da cidade ... de crescer muito, de ter espaço para os animais } \\
\text {... também das relações dos parques lineares [...] }\end{array}$ \\
\hline Museu & $\begin{array}{l}\text { [...] projetos que a gente vem fazendo ... por exemplo a Noite no Museu [...] } \\
{[\ldots] \text { são crianças }[\ldots . . .] \text { passam a noite conosco aqui }[. . .] \text { o trabalho em si são }} \\
\text { diversas atividades ... é, são oficinas, brincadeiras, temos um tour no museu } \\
\text {... que é feito um trabalho também ... de conhecimento do museu que daí ... } \\
\text { a gente faz um pouquinho diferente ... do que o monitoramento normal [...] }\end{array}$ \\
\hline $\begin{array}{l}\text { Aquário } \\
\text { Municipal }\end{array}$ & $\begin{array}{c}\text { [...] o rio Paraná foi altamente impactado pela construção da Itaipu [...] e } \\
\text { muitas espécies que estão lá no aquário [...] hoje são extintas no rio Paraná } \\
{[\ldots . .]} \\
\text { [...] um teatro de fantoche na frente de um aquário [...] e tratava temas ... } \\
\text { jogar sujeira no rio ... o teatrinho de fantoche ficava na frente de um aquário } \\
\text {... então durante a fala ... a gente jogava latinha de coca-cola dentro do } \\
\text { aquário ... pra mostrar que o peixinho ficava com medo [...] }\end{array}$ \\
\hline
\end{tabular}

Fonte: Autoria própria (2017).

Nessa categoria, observamos como esses espaços podem ter grande influência na sociedade e, principalmente, no desenvolvimento das crianças. 0 Parque das Aves é um bom exemplo, que, além das atividades desenvolvidas na trilha, buscou confeccionar uma revista para divulgar a Educação Ambiental no município.

Já o Museu realiza uma atividade na qual as crianças passam uma noite no Museu, realizando diversas oficinas, o que proporciona às crianças o convívio umas com as outras, inserindo-se em culturas diferentes, como, por exemplo, a da história e a ciência.

Trabalhamos também com atividades lúdicas, pois, durante as atividades monitoradas com grupos de crianças, o aquário realiza um teatro de fantoches visando à conscientização da importância de não se jogar lixo nos rios.

E o último indicador é aquele que diz respeito ao estético e afetivo. Quanto a ele, apresentamos o Quadro 5.

\begin{tabular}{|c|c|}
\hline Locais & Indicador Estético/Afetivo \\
\hline $\begin{array}{c}\text { Parque } \\
\text { das Aves }\end{array}$ & $\begin{array}{c}\text { [...] acreditamos que somente o simples contato com a natureza ... já } \\
\text { sensibiliza e auxilia na mudança de comportamento ... o simples contato, } \\
\text { [...] usufruir do Silêncio ... dos aromas ... sensibilizando por esse contato ... } \\
\text { né ... pela apreciação das Belezas ... essas belezas naturais passam tão } \\
\text { despercebidas pela pessoa ... então assim ... a gente trabalha dentro deste } \\
\text { conceito ... assim de valorizar aquilo que para nós ... o que mais tem valor na } \\
\text { vida né [...] }\end{array}$ \\
\hline $\begin{array}{c}\text { Museu } \\
\text { Municipal }\end{array}$ & $\begin{array}{c}\text { [...] a visita no Museu é cultura ... né então assim todos nós teríamos que ter } \\
\text { um pouquinho de cultura }[\ldots] \\
{[\ldots] \text { bem importante }[\ldots] \text { as pessoas virem visitar ... fazer essa visita ... como é }} \\
\text { aumentar um pouquinho cultura }[\ldots]\end{array}$ \\
\hline $\begin{array}{l}\text { Aquário } \\
\text { Municipal }\end{array}$ & $\begin{array}{l}\text { [...] quando você conhece coisas novas ... você não precisa sentar numa } \\
\text { cadeira ou ler ... um livro... pra você ter cultura a cultura faz parte da nossa }\end{array}$ \\
\hline
\end{tabular}


vivência ... eu percebo que quando as pessoas visitam o aquário ... elas estão adquirindo algum tipo de cultura [...]

[...] uma coisa que eu vi muito ... acontecer no aquário ... nos primeiros meses que ele funcionou ... lá em 2007 ... as pessoas entravam no aquário e davam uma volta super rápida ... e em menos de dois minutos elas saíam e saíam bufando falando assim ... 'ah mais não tem nada de novo'... hoje eu percebo que as pessoas entram lá com mais calma ... param pra observar o peixe ... param pra observar coisas que não estão assim na primeira vista ... por exemplo um peixe em particular ... que fica escondido no meio das pedras ... e aí elas começam a compreender várias coisas ... que vão desde a sua educação ... como cidadão de não pôr a mão no vidro respeitar [...]

Fonte: Autoria própria (2017).

Partindo das respostas dos coordenadores, observamos que um dos principais aspectos da visita é o de proporcionar aos visitantes um momento de lazer, bem como, uma mudança de hábito, uma nova maneira de interação com esses tipos de espaços. Isso fica evidente na fala do coordenador do aquário, quando ele diz que, há alguns anos atrás as pessoas realizavam a visita de forma rápida e saíam questionando o fato de não haver nada de novo, sendo já hoje as pessoas realizam a visita com mais calma, observando os detalhes nos tanques.

Após analisadas as respostas, podemos dizer que esses espaços têm muito a contribuir com as atividades realizadas em sala de aula, visto que cabe ao professor adaptar as visitas com o propósito de suas aulas. Sobre isso, a responsável pelo Museu reforça que as atividades do roteiro "Conhecendo Toledo" já são realizadas em conjunto com os professores,

[...] principalmente com do roteiro Conhecendo Toledo os professores fazem esses trabalhos em sala de aula e depois de estudar a história do município, eles vêm para o Museu...

Ou seja, cabe ao professor direcionar a atividade que será realizada nesses espaços. Esse direcionamento deve ocorrer de maneira que essas visitas possibilitem o acesso ao conhecimento científico específico ou, apenas, espaços que são disponibilizados para atividades de lazer aos estudantes, os famosos "passeios" escolares.

Para finalizar, acreditamos que esses espaços possam contribuir não apenas para Alfabetização Científica dos estudantes, mas para a de todos os que visitam os espaços e neles encontram a oportunidade de conhecer um pouco mais da sua cidade e da ciência.

\section{CONSIDERAÇÕES FINAIS}

Muitas vezes moramos em cidades que apresentam diversos locais que podem nos proporcionar, além de momentos de lazer, muitos tipos de conhecimentos, sejam eles científicos, sociais, culturais...

Nessa perceptiva, por meio das entrevistas realizadas com os coordenadores do Parque das Aves, do Aquário Municipal e do Museu, identificamos que esses espaços têm a potencialidade de proporcionar diversos tipos de conhecimentos aos que os visitam. É importante salientar que diversas atividades são realizadas nesses locais e são diferentes os casos de interação entre público e monitor. 
Identificamos que os principais visitantes desses espaços são grupos de estudantes das escolas da rede municipal de ensino da cidade de Toledo, mas esses espaços também recebem visitas de moradores de diversos locais do Brasil e do exterior.

Refletindo sobre as atividades desenvolvidas, visitantes e o espaço físico, acreditamos que ainda há muito a ser melhorado, visto que os temas e os assuntos abordados em cada espaço são muito restritos. Se cada espaço fosse explorado de uma maneira diferenciada, seria mais amplo o conhecimento por parte dos visitantes. Por isso cabe ao professor realizar e organizar atividades nesses locais, e assim, em conjunto com os monitores, proporcionar aos estudantes meios que favoreçam o desenvolvimento da Alfabetização Científica. 


\title{
Scientific literacy indicators: A study in non- formal spaces of the city of Toledo, PR
}

\begin{abstract}
The present work presents a study on the following spaces of non-formal education, present in the city of Toledo, PR: Bird Park and Municipal Aquarium Romolo Martinelli, both installed next to the Diva Paim Barth Ecological Park and the Willy Barth Historical Museum. In this study we conducted a focused interview with the coordinators of the spaces, to identify how the activities are carried out, as well as, which are their main visitors. After the interview transcripts, we conducted a content analysis according to Bardin (2011). The categories are according to the indicators of Scientific Literacy by Cerati (2014), which are Scientific Indicator, Institutional Indicator, Interface/ social Indicator and Aesthetic/Affective Indicator. The analysis provided subsidies to conclude that the spaces receive visitors from several cities in Brazil, as well as from abroad, however, the main visitors are students of municipal schools in the city. We also identify that several activities are performed in these spaces, and these can provide different knowledge to those who visit them.
\end{abstract}

KEYWORDS: Scientific culture. Museums. Aquarium. Forest garden. Scientific dissemination. 


\section{REFERÊNCIAS}

AFONSO, A. M.; SASSERON, L. H. Alfabetização científica dos alunos e a importância do papel do professor nesse processo. In: ENCONTRO NACIONAL DE PESQUISA EM EDUCAÇÃO EM CIÊNCIAS, 8., 2011, Florianópolis - SC, Anais eletrônicos... Florianópolis: Abrapec, 2011.

BARDIN, L. Análise de conteúdo. Tradução Luís A. Pinheiro, São Paulo, 2011.

BRASIL. Base Nacional Comum Curricular, 2016. Disponível em: <http://basena cionalcomum.mec.gov.br/\#/site/inicio1>.

Orientações Curriculares Nacionais para o Ensino Médio. 2006.

Disponível em: <http://portal.mec.gov.br/seb/arquivos/pdf/book_volume_02 _internet.pdf>. Acesso em: 20 mai 2017.

BYBEE, R. W. Achieving scientific literacy. The science teacher, v. 62, n. 7, p. $28-$ 33, 1995.

CERATI, T. M. Educação em jardins botânicos na perspectiva da alfabetização científica: análise de uma exposição e público. Tese (Doutorado - Programa de Pós-Graduação em Educação. Área de Concentração: Ensino de Ciências e Matemática) - Faculdade de Educação da Universidade de São Paulo) 2014.

DEBOER, G. Scientific literacy: another look at its historical and contemporary meanings and its relationship to science education reform. Journal of Research in Science Teaching, v. 37, n. 6, p. 582-601, 2000.

ESCODINO, D. A.; GÓES, C. S. Alfabetização científica e aprendizagem significativa: situação de alunos de escolas estaduais do Rio de Janeiro com relação a conceitos de biologia molecular. Investigações em Ensino de Ciências, v. 18, n. 3, pp. 563-579, 2013 563. Disponível em:

<http://www.if.ufrgs.br/ienci/artig os/Artigo_ID343/v18_n3_a2013.pdf>. Acesso em: 10 maio 2017.

GHILARDI-LOPES, N. P. Educação ambiental e os parques - áreas verdes das cidades. 2014. Disponível em: <http://www.areasverdesdascidades.com.br/20 14/09/artigo-sobre-educacao-ambiental-e-os.html>. Acesso em: 19 mai. 2017.

GIL, A. C. Métodos e técnicas de pesquisa social. 6. ed. São Paulo: Atlas, 2008. 
GOHN, M. G. Educação não-formal, participação da sociedade civil e estruturas colegiadas nas escolas, 2016. Disponível em: $<\mathrm{http}$ ://escoladegestores.mec.gov. br/site/8-biblioteca/pdf/30405.pdf>. Acesso em: 10 mai. 2017.

KRASILCHIK, M.; MARANDINO, M. Ensino de ciências e cidadania. São Paulo: Moderna, 2004.

LAUGKSCH, R. C. Scientific literacy: a conceptual overview. Science Education, v. 84, n. 1, p. 71-94, 2000.

LEITE, R. F. Dimensões da alfabetização científica na formação inicial de professores de química. Tese de pós-graduação em Educação para a Ciência e a Matemática do Centro de Ciências Exatas da Universidade Estadual de Maringá. Maringá 2015.

LOPES, C. S.; PONTUSCHKA, N. N. Estudo do meio: teoria e prática. Geografia, Londrina, v. 18, n. 2, p. 173-191, 2009.

MARTINS, C. E. M. A.; BARACHO, R. M. A.; BARBOSA, C. R. Os museus na era da informação: análise do uso de recursos tecnológicos. IV Colóquio Ibero Americano: Paisagem Cultural, Patrimônio e Projeto. Disponível em: <http:// www.forumpatrimonio.com.br/paisagem2016/artigos/pdf/449.pdf>. Acesso em: 29 mai. 2017.

MENGHINI, F. B.; GUERRA, A. F. S. Trilhas interpretativas: caminhos para a educação ambiental. ANPEDSUL, Itajaí SC, 2008.

Diretrizes Curriculares da Educação Básica Ciências. Disponível em:

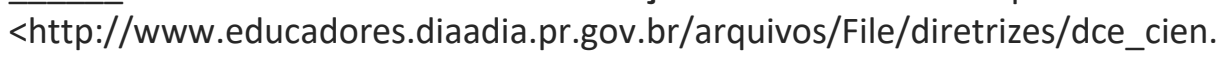
Pdf>. Acesso em: 10 mai. 2017.

Diretrizes Curriculares da Educação Básica Física. Disponível em:

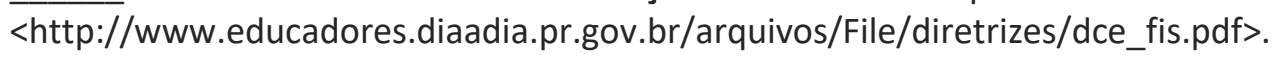

Diretrizes Curriculares da Educação Básica Química. Disponível em:

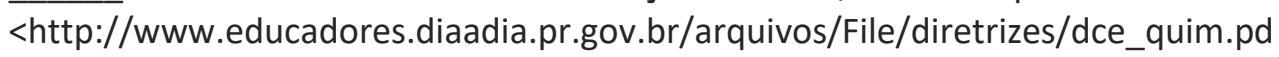
$\mathrm{f}>$.

PEREIRA, I. S. D.; MACIEL, C. P.; PEIXOTO, C.; COUTINHO, R. R. Princípios para a criação de uma trilha ecológica interpretativa, com elementos socioculturais regionais, em um fragmento de restinga no município de São Francisco de Itabapoana. IV Seminário Regional sobre Gestão de Recursos Hídricos, 2014. 
SASSERON, L. H.; CARVALHO, A, M. P. Alfabetização científica: uma revisão bibliográfica. Investigação em Ensino de Ciência, v. 16, n. 1, p. 59-77, 2011.

SHEN, B. S. P. Science literacy. American Scientist, v. 63, n. 3, p. 265-268, 1975.

SILVA, L. N.; GRYNSZPAN, D. A parceria educação formal - não formal para a apropriação da química no cotidiano. In: ENCONTRO NACIONAL DE PESQUISA EM EDUCAÇÃO EM CIÊNCIAS, 11, 2015, Águas de Lindoia - SP, Anais eletrônicos... Águas de Lindoia: Abrapec, 2015.

SMITH, M. K. 'What is non-formal education?'. The encyclopedia of informal education. 2001. Disponível em: <http://infed.org/mobi/what-is-non-formaleducation/>. Acesso em: 14 mai. 2017.

Recebido: 29 mai. 2017

Aprovado: 29 set. 2017

DOI: 10.3895/actio.v2n1.6801

Como citar:

FERREIRA, M.; ALVES, G. L.; CUNHA, M. B. da; LEITE, R. F. Indicadores de Alfabetização Científica: um estudo em espaços não formais da cidade de Toledo, PR. ACTIO, Curitiba, v. 2, n. 1, p. 499-516, jan./jul. 2017. Disponível em: <https://periodicos.utfpr.edu.br/actio>. Acesso em: XXX.

Correspondência:

Matheus Ferreira

Rua Marcilio Dias n44, 85909-580, Vila Pioneiro, Toledo, Paraná, Brasil.

Direito autoral: Este artigo está licenciado sob os termos da Licença CreativeCommons-Atribuição 4.0

Internacional.

(c) (i) 